\title{
Alternative management in a case of placenta accreta with previous caesarean
}

\author{
Rajani M. Parikh*, Kanaklata Nakum, A. V. Gokhle
}

Department of Obstetrics \& Gynecology, Sir T Hospital and Government Medical College, Bhavnagar, Gujarat, India

Received: 24 November 2012

Accepted: 14 December 2012

*Correspondence:

Dr. Rajani M. Parikh,

E-mail: rajnimaulik@yahoo.com

\begin{abstract}
The rate of caesarean is increasing day by day, and with it the chance of repeat caesarean. This has led to a rise in the chance of occurrence of placenta accreta. Control of bleeding is the main goal in such cases, which usually necessitates hysterectomy. But alternative methods are useful when retaining fertility is important. We present this case of a $30 \mathrm{yr}$ old female who was admitted as a case of central placenta previa with previous caesarean. Per operatively, placenta was attached along the incision and baby was delivered by separating the placenta attached above the upper margin of incision. On attempting to remove the placenta attached to lower part of incision, it was found to be adherent along the previous scar. So placenta was removed piece meal, some part was left behind. Box sutures were taken over that part and uterine packing was done to control the bleeding. Post operatively the patient was fine and given injection Methotrexate on 8th day following the regime of 1, 3, 5, 7 days. She failed to expulse the placenta by 6 wks, so D\&E was done and retained products were removed. Leaving the placenta in situ followed by Methotrexate and interval removal of placenta can thus be helpful in conserving the uterus and hence, the fertility.
\end{abstract}

Keywords: Placenta Accreta, Conservative management

\section{INTRODUCTION}

Placenta accreta is a condition characterized by abnormal adherence of either in whole or a part of placenta to the uterine wall. The true incidence of placenta accrete is difficult to quantify accurately but it is estimated to be between $1 / 7000$ to $1 / 2000$ deliveries in developed countries. Over the last 50 years, the incidence of placenta accreta is estimated to have increased ten-fold. ${ }^{1}$

\section{CASE REPORT}

A 30 years aged Mrs XYZ, G2P1A0 with 32 weeks of pregnancy with previous caesarean was admitted as a case of placenta previa with complaints of bleeding per vaginum of 1 pad partially soiled and fever since 3 days. Her LMP was not known. Her 1st delivery was a full term caesarean 4 years back.

On admission, her pulse was 140/min and BP was 120/70. Pallor was ++ , Urine albumin was trace. On per abdomen examination, scar of caesarean present, uterus was 32 weeks, relaxed, cephalic floating, FHS 156/min, No scar tenderness. On speculum examination: slight bleeding was present and os was closed.

On investigation, hemoglobin was $8.0 \mathrm{gm} \%$. Serum widal was positive. Urine showed plenty of pus cells. Liver and renal functions as well as S. TSH were normal. ECG showed sinus tachycardia. Ultrasonography showed single live intrauterine fetus of 32 weeks, cephalic with placenta previa. Placenta was central, completely covering the internal os.

She was given 3 red cell concentrate and antibiotics were started. She was kept on expectant line of management with regular monitoring for bleeding, vitals and fetal growth.

At 37 weeks, elective caesarean was done. Lower segment was well formed with prominent dilated vessels over lower segment and traversing towards the bladder base. So incision was placed slightly higher, above the previous scar along an avascular plane. On placing 
incision over lower segment, placenta came into the view, which was attached along the previous scar. Baby was approached only after separating the placenta attached over the upper margin of incision. Membrane was ruptured. Baby was delivered by vertex, male live $3.2 \mathrm{~kg}$.

Attempt was made to remove the placenta attached to lower part of incision. There was no plane of cleavage between the decidua and placenta. So, placenta was removed piece meal with some part being left behind. There was torrential haemorrhage. Patient developed severe hypotension and was started on injectable dopamine and dobutamine. Box sutures were taken to control the bleeding. There was slight oozing so the uterus was packed with roller gauze, with one end of gauze being pushed in vagina, and then the incision was closed with vicryl no. 1. Care was taken so that the gauze was not stitched while closing the incision. Haemostasis was secured. Patient maintained her vitals with dopamine and dobutamine. Patient was given 4 units PCV, 1 FFP and higher antibiotics. Injection oxytocin was continued post operatively for 12 hours. Inj. dopamine and dobutamine were tapered postoperatively and omitted within 12 hours. After 18 hours, the pack was removed vaginally after starting injection oxytocin 20 units, which was continued for 4 hours. There was no active bleeding at that time. The Post-operative period was uneventful.

Injection methotrexate was given on 8th day following the regime of $1,3,5,7$ with injection folinic acid on alternate days. Lochia remained healthy with soakage of 1 pad per day during this time. Patient was discharged on 16th day with oral antibiotics, which were continued for 7 days. At that time, uterus was subinvoluted to 14-16 wks size \& ultrasonography showed presence of retained products. She was advised to follow up weekly and/or if heavy bleeding per vaginum. She stopped bleeding from 20th day.

At 6 wks, she came with complain of bleeding since 3 days with 2 pads soaked per day. Uterus was subinvoluted to $14-16$ wks size with os closed. USG showed retained placenta with hypervascularity. Her haemoglobin was $9.9 \mathrm{gm} / \mathrm{dL}$, total count, platelet count, liver and renal function tests were normal. She was readmitted and D\&E was done in the presence of anaesthetists. Patient had been counseled that hysterectomy might have to be done if heavy bleeding occurs. About 100 gms of placental bits were removed on D\&E. 1 unit of blood was given. On discharge uterus was 10 weeks without any retained products.

\section{DISCUSSION}

The mainstay of traditional management in cases of placenta accreta is abdominal hysterectomy and its prompt undertaking has been shown to reduce maternal mortality. However, it is often delayed, as it is perceived as a difficult procedure at caesarean delivery and the complication rate may be significant. Also, it ends fertility and may cause serious psychological consequences.

Leaving the placenta in situ is possibly the most important aspect of conservative management. If there is a high index of suspicion of accreta then, unless the placenta can be removed with the minimum effort and a cleavage plane can be found easily, no further attempts to remove it should be made. ${ }^{2,6}$ In this manner, the fused area between the placenta and the myometrium is not disrupted and it is expected that bleeding will be minimal. If this is the case during normal delivery, the umbilical cord can be cut short and the placenta left undisturbed in situ. And if it occurs at the time of caesarean section, uterus closed in routine fashion. It has implications for infection and therefore the woman is generally covered with broad spectrum intravenous antibiotics for a variable time period. ${ }^{6}$ It is possible that the use of methotrexate hastens the resolution of the placenta. A number of reports have described of passing of placental tissues after 5 and 13 days following intensive intravenous methotrexate $7,8,9,10$ and 18 days following high-dose oral methotrexate. ${ }^{11}$ Though women not treated with methotrexate do not appear to be unduly disadvantaged. ${ }^{12}$ Outcome generally does not vary whether methotrexate is used or not.

There is no consensus as to whether the placenta should be removed in the postpartum period or left to (presumably) resorb or to be passed spontaneously. One option to reduce bleeding is to ascertain by doppler ultrasound when the vascularity of the placenta has ceased and then consider removing it. ${ }^{3}$ This does not guarantee success. ${ }^{1}$ Leaving the placenta in situ with planned interval removal, if nothing else, may facilitate a more planned approach to potentially high-risk surgery. Though complications of leaving the placenta in situ have also been reported. ${ }^{1}$

It is possible to excise the placental site. ${ }^{13}$ If the area of accreta is focal and the majority of the placenta has been removed, then a wedge resection of the area can be performed. ${ }^{1}$

Bilateral uterine artery embolisation, argon beam coagulation of the placental bed and Pelvic artery ligation (anterior division of internal iliac or uterine artery) have been mentioned with varying success. ${ }^{14-16}$

If the placenta has been left in situ, the woman requires follow-up to ensure the resolution of placental tissue. This is done with a combination of clinical assessment, ultrasound examination and serum $\mathrm{B}-\mathrm{hCG}$ assay.,7,11 Significant reduction of $\beta-$ hCG to low levels does not, however, mean that uterine hemorrhage will not occur and it has been omitted with no apparent deleterious effects in a number of cases. ${ }^{6,7,11}$ Ultrasonography is useful in assessing placental involution ${ }^{2,7,11}$ and has been combined with colour Doppler imaging to determine placental vascularity. ${ }^{2,3}$ 
Conservative management should be specifically considered in women in whom placenta accrete is suspected antenatally, when bleeding is minimal and when preservation of fertility is of particular importance.

\section{REFERENCES}

1. Armstrong CA, Harding S, Dickinson JE. Clinical aspects and conservative management of placenta accreta. The Obstetrician \& Gynaecologist 2004;6:132-7.

2. Hollander DI, Pupkin MJ, Crenshaw MC, Nagey DA. Conservative management of placenta accreta. A case report. J Reprod Med 1988;33:74-8.

3. Dunstone SJ, Leibowitz CB. Conservativ management of placenta praevia with a high risk of placenta accreta. Aust N Z J Obstet Gynaecol 1998;38:429-33.

4. Mussalli GM, Shah J, Berck DJ, Elimian A, Tejani N, Manning FA. Clinical perinatal/neonatal case presentation. Placenta accreta and methotrexate therapy: three case reports. J Perinatol 2000;5:3314.

5. Taylor AA, Sanusi FA, Riddle AF. Expectant management of placenta accreta following stillbirth at term: a case report. Eur J Obstet Gynecol Reprod Biol 2001;96:220-2.

6. Kitchen DH. Placenta accreta, percreta and praevia accreta. Aust N Z J Obstet Gynaecol 1978;18:23841.

7. Komulainen MH, Vayrynen MA, Kauko ML, Saarikoski S. Two cases of placenta accreta manage conservatively. Eur J Obstet Gynecol Reprod Bio 1995;62:135-7.

8. Gibb DM, Soothill PW, Ward KJ. Conservative management of placenta accreta. $\mathrm{Br} \mathrm{J}$ Obstet Gynaecol 1994;101:79-80.

9. Arulkumaran S, Ng CS, Ingemarsson I, Ratnam SS Medical treatment of placenta accreta wit methotrexate. Acta Obstet Gynecol Scand 1986;65:285-6.

10. Buckshee K, Dadhwal V. Medical management of placenta accreta. Int J Gynaecol Obstet 1997;59:478.

11. Riggs JC, Jahshan A, Schiavello HJ. Alternative conservative management of placenta accreta. A case report. J Reprod Med 2000;45:595-8.

12. Gupta D, Sinha R. Management of placenta accreta with oral methotrexate. Int $\mathbf{J}$ Gynaecol Obstet 1998;60:171-3.

13. Bennett MJ, Sen RC. 'Conservative' management of placenta praevia percreta: report of two cases and discussion of current management options. Aust N Z J Obstet Gynaecol 2003;43:249-51.

14. Descargues G, Douvrin F, Degre S, Lemoine JP, Marpeau L, Clavier E. Abnormal placentation and selective embolization of the uterine arteries. Eur J Obstet Gynecol Reprod Biol 2001;99:47-52.

15. Scarantino SE, Reilly JG, Moretti ML, Pillari VT. Argon beam coagulation in the management of placenta accreta. Obstet Gynecol 1999;94:825-7.

16. Evans S, McShane P. The efficacy of internal iliac artery ligation in obstetric hemorrhage. Surg Gynecol Obstet 1985;160:250-3.

DOI: $10.5455 / 2320-1770$. ijrcog001012

Cite this article as: Parikh RM, Nakum K, Gokhle

AV. Alternative management in a case of placenta accreta with previous caesarean. Int J Reprod Contracept Obstet Gynecol 2012;1:58-60. 